\title{
An Assessment of Educational leaders' Multicultural Competences in Ethiopian Public Universities
}

\author{
Abeya Geleta, PhD \\ Frew Amsale, Lecture \\ Jimma University, College of Education and Behavioural Sciences, \\ Department of Educational Planning and Management
}

doi: 10.19044/esj.2016.v12n10p387 URL:http://dx.doi.org/10.19044/esj.2016.v12n10p387

\begin{abstract}
Multicultural Competences of higher education leaders refer directly to the multicultural knowledge, attitudes and skills of the leaders which is the focus of the present study. The demographic changes and the subsequent diversity in Ethiopian HEIs strongly demands the HEIs to be multiculturally competent, their leaders should in turn have the necessary multicultural competencies. In line with this, the multicultural competences of the educational leaders of Ethiopian public universities were investigated. The mixed-methods research approach was used in the study, including semistructured interviews and questionnaires. Academic and administrative officials, office workers and teachers were included in the study as sources of data. Multi-stage, simple random and purposive sampling techniques were employed to select 316 participants for the study. Inferential statistics including mean, standard division, t-tests and one-way ANOVA were used to analyze the quantitative data. The university leaders, academic and administrative staff did not have a considered perspective on pluralism. In addition, there were limited spaces and opportunities for the staff to develop skills and experience in the management of difference as an important aspect of their work and with their interaction with other members of the university community. The staff associations were weak and poorly equipped to provide or promote opportunities for skills development in the management of diversity. Lecturers did not generally receive any preparation on managing within a multicultural setting. The findings confirm the position that the need to prepare university leaders with multicultural knowledge, skills, and dispositions. It is imperative that university leadership adopt multicultural competence as an essential competency within their profession, continue to seek out opportunities to further enhance personal multicultural competence, and infuse it into their daily practices.
\end{abstract}


Keywords: Multicultural competence; leadership; attitudes, knowledge and skills

\section{Introduction}

Managing diversity is a continuous process aims at creating a wholesome, inclusive environment by making use of the talents and capabilities of the diversified populations bring in to an organization, community or society. In this globalized and interconnected era the sustenance of organizations by large depends up on their capability of managing diversity in which the knowledge, skills, abilities, and attitudes of all workers are embraced towards the success of the organizations (Connerley and Pedersen, 2005). To this end, diversity has become of increasing interest to corporations, the public sector and other not-for-profit organisations (Lumby \& Coleman, 2007). This is of no exception to educational institutions. In this regard, Dimmock and Walker (2005) stated that, “... given the multi-ethnic nature of schools around the world, leaders nowadays shoulder responsibility for shaping their organizations in ways that value and integrate heterogeneous groups into successful learning communities for all ...” Consequently, as Webb, Darling, and Alvey (2014) state organizations are increasingly demanded to exert significant efforts in developing their multicultural capabilities to ensure their competitive advantage.

Organizations' multicultural competence, however, cannot be achieved in a vacuum. The success of organizations in this regard chiefly depends on the skills and abilities of their leaders to manage diversity and implement increasingly complex strategies (Chuang, 2013). This is true because leaders, while they may not be the only people with power in an organisation, by virtue of their formal and informal roles of authority, have the possibility to disturb power relations (Lumby \& Coleman, 2007) and to set the tone for the climate of the organization and the expectations for the company (Connerley and Pedersen, 2005). Besides, today's leaders need to deal with complex, heterogeneous, and diverse contexts (Connerley and Pedersen, 2005) in which the leadership skills and techniques that have been proven to be effective in a relatively homogenous organizations became obsolete in the faces of diverse work forces (Lumby \& Coleman, 2007). Consequently, effective leadership is increasingly viewed as inclusive, empowering, collaborative, and authentic aspect (Chin, 2009). Leaders then, to be successful must be aware of important cultural dimensions and understand how these dimensions can influence their working relationship with others from dissimilar cultures (Webb, Darling, \& Alvey, 2014). Hence, the locus of leaders pertaining to diversity is of vital concern (Lumby \& Coleman, 2007). 
In general, the success of organizations in managing diversity and thereby to ensure their competitive advantage requires the organizations to be multiculturally competent which in turn needs their leaders " ... to be global in focus and sensitive to respecting people from around the world and from very diverse backgrounds, beliefs, and mores ..." (Chin, 2009, p. 89). That means the multicultural nature of today's organizations needs leaders with multicultural competencies which by the words of Rockstuhl et al., (cited in Chuang, 2013) known as the capability of cultural intelligence or cultural quotient.

Multicultural leaders need to be context-sensitive. They need a broad interest and an eagerness to absorb new signals, including inspiration from fields like history, geography, religion, literature, and art. Leading in a multicultural setting calls for different attitudes and skills: restraint in passing judgment and the ability to recognize that familiar tunes may have to be played differently. In order for leaders to sense the cultural context of a situation and to consider the uniqueness of the relationships, they may need to recognize various cultural mental models of leadership to raise their awareness and increase their sensitivity (Webb, Darling, \& Alvey, 2014).

At individual level, literature generally discusses three main components to becoming multiculturally competent. These are cultural attitude, cultural knowledge and skills. These three main components are found in many models of cultural competence and in many different professions (Sue, 2001; Kim-Godwin, et al., 2001). Cultural attitude refers to a sensitivity and understanding of one's own and others cultural identity as it manifests itself through ones beliefs, values and practices as well as biases. Attitudes refer to the thoughts, beliefs, and biases that members of the organization may have regarding culturally diverse populations. This element refers to the respect and value an organization gives to staff and students coming from different backgrounds. Variations in communication style, behaviours, values, and attitudes need to be seen as legitimate and not as something that must be tolerated.

Cultural knowledge is related with having knowledge of other cultures' beliefs, values and practices, which allow for an understanding of different worldviews. For example, it be conceptualised as university leaders' knowledge concerning the dynamics that occur when two or more groups confront stereotypes and political or power differentials, knowledge of differences in communication styles, etiquette, problem-solving methods and the like. Cultural skills need for having the skills to interact effectively with diverse cultures. These components are presented as a three-factor model and have informed much of the existing work on cultural competence. This model has generated a substantial amount of empirical research and is 
the backbone of the most commonly-used competency assessment scales (Abreu, Chung \& Atkinson, 2000).

Today, as institutions of higher education are made of culturally diverse student and faculty populations, leaders' Multicultural competence is of paramount importance (Ameny-Dixon, 2004). Despite the fact that numerous studies have been carried out to study multiculturalism in both Western and non-Western countries, in considering leadership for and with diversity in education, there is a difficulty in that relatively little relevant research has been undertaken specifically in educational contexts (Lumby \& Coleman, 2007),(Andersen, 2012). The worst is in African universities where there is a clear lack of research on issues of diversity where diversity is at their midst (Cross, 2004).

\section{Context of the Study}

Ethiopia is geographically located in East Africa with a total area of 1,127,127 square kilometres. Djibouti, Eritrea, the Republic of the Sudan, the Republic of the Southern Sudan, Kenya, and Somalia border the country. It is located in one of the continent's most politically unstable and economically vulnerable sub-regions - the Horn of Africa. It is a country with diverse ethnic and linguistic groups - where over 80 different languages are spoken (MOI, 2004). It can be characterized as a mosaic of nations, nationalities and peoples, as well as linguistic groups. Ethiopia, with a population of about 84 million (World Bank, 2012), is the second most populous country in Sub-Saharan Africa.

Ethiopia experienced a change of government in 1991 that led to reforms in the education system of the country. The educational reforms include a new education policy, decentralization of educational administration, new school curricula, and the use of vernacular languages of nationalities as media of instruction. As result of these reforms, the Ethiopian higher education system has been undergoing massive expansion both in the public and private domains. The number of public higher education institutions that was only two until 1990s, has now reached about 32. Parallel to this rapid expansion, a huge number of students from different backgrounds are joining the higher education institutions. The total degree enrolment in both public and private higher education institutions increased from 203,399 in 2006/07 to about 477, 693 in 2010/11, with an annual average growth rate of $21.8 \%$. The expansion in tertiary education has also brought about an increase in the number of academic staff from 8,355 in 2006/07 to 17,402 in $2010 / 11$, with a $20.1 \%$ annual increase (MoE, 2010/11:59).

In this context, the Ethiopian higher education institutions (HEIs) need to be measured, among others, by the extent to which they address 
cultural pluralism, mutual co-existence and unity within diversity. In milieu of the workers and students diversity in the Ethiopian HEIs, good leadership calls for multicultural competence in the appreciation of differences, tolerance, respect, and positive attitudes across cultures. Efforts made to address such values at individual and organisational levels contribute to mutual co-existence and harmony in the country.

\section{Statement of the problem}

Multicultural competence is of paramount importance for institutions of higher education today as they are made of culturally diverse student and faculty populations. In line with this, the Federal Democratic Republic of Ethiopia (FDRE), Higher Education proclamation No. 650/2009 has identified that one of the objectives of the HEIs is to promote democratic culture and uphold multicultural community life (FDRE, 2009). Besides, the Higher Education Development program (HEDP) indicated that one of the future directions of the HE development is facilitating for unity that is based on multiculturalism, recognition and appreciation.

Moreover, Ethiopian HEIs will continue to experience, more and more diversity in terms of their students' religious, linguistic and ethnic compositions (MoE: 2011). The upcoming changes in the demographics trends of the student body and their workforce, and the consequent need for an inclusive education and multicultural campus environment strongly demands higher education institutions to promote diversity and multiculturalism in their campuses. The situation in turn requires educational leaders in the HEIs to shoulder the responsibility for shaping their institutions in such ways that diversified groups of students and the work force are equally valued and integrated into successful learning communities (Dimmock and Walker, 2005).

The trends of the last decade showed that HEIs have been experiencing several diversity related conflicts of students that resulted from the lack of multicultural skills to handle differences in religion, ethnicity and linguistics amongst themselves. From our own personal experiences as university instructors, too, we have witnessed that the universities have usually been reactive to most of these conflicts. The existing multicultural situation of the universities by the large is the implications of the leaders' multicultural competencies. Because it is leaders, particularly those at the top who are responsible to lead in different ways as organisations change in their nature, with many more diverse and fluid ways of working (Lumby \& Coleman, 2007). Besides, as to the knowledge of these researchers, multiculturalism in Ethiopian higher education in general and the multicultural competencies of educational leaders in particular, have not been adequately studied in the public universities. 
It is hence, for this reason that this study was aimed to assess the extent of the multicultural competencies of educational leaders in Ethiopian public universities. The assessment is crucial as it helped to understand the multicultural competences of educational leaders of Ethiopian HEIs and thereby help to identify some of important leadership development components for HEI leadership development.

To achieve this purpose, the study has raised the following basic questions:

1. To what extent do educational leaders in public universities are equipped with multicultural skills, knowledge and attitudes?

2. To what extent educational leaders in Ethiopian public universities are effective in applying their multicultural skills, knowledge and attitudes towards leading diversity?

3. What are the major challenges/gaps observed in relation to educational leaders' multicultural competence (multicultural skills, knowledge and attitudes) in Ethiopian public universities?

\section{Research Objectives}

The overall purpose of this study was to assess the multicultural competences of educational leaders of Ethiopian public universities.

\section{Specific objectives of the study}

1. Examine the extent that educational leaders in public universities are equipped with and effective in applying multicultural skills, knowledge and attitudes.

2. Investigate the major challenges/gaps observed in relation to educational leaders' multicultural competence (multicultural skills, knowledge and attitudes) in Ethiopian public universities.

\section{Research Design and Methodology \\ The Research Design}

The study applied mixed methods research approach. The use of the particular mixed methods research makes use of both quantitative and qualitative methodological approach to answer a particular research problem (Jupp, 2006). Either of the quantitative or qualitative approaches by themselves is inadequate to address complex problems, hence it is through mixed research that we can broaden understanding by incorporating both qualitative and quantitative research (Creswell, 2009). In this study, the mixed methods research approach was used by concurrently collecting and analyzing both qualitative and quantitative data in order to bring about more reliable result. The qualitative data were collected from educational leaders 
through interviews and the quantitative data were collected from teachers, workers and leaders of the public universities through questionnaires.

\section{Sources of the data}

University vice presidents, administrators, college deans, department heads, teachers and workers were included in the study as primary sources of data. The inclusion of the presidents, college deans, administrators and department heads as a source of data was made based on the assumptions that they could provide an insight as to the levels of the multicultural competences of educational leaders from the educational leaders' perspectives. However, there might be a tendency of leaders' self-reporting as the subject of the study mainly related to their performances. In this case, it was useful to get an insight of multicultural competences of the universities from the teachers and workers perspectives. So that the balanced view of the issue might have been maintained and in turn helped to arrive a better understanding of the issue under consideration.

\section{Sample Size and Techniques}

The public universities in Ethiopia can be categorized in to three based on their generations. From each of the three generations, one sample university was selected by using simple random sampling methods. Simple random sampling technique was used to give each of the universities an equal chance to be included in the sample. As to the selection of the sample colleges and departments', multistage sampling technique was employed. From each of the sample universities, five colleges were included in the study through simple random sampling technique and from each of the sample colleges three sample departments were included in the study randomly. All the vice presidents of the sample universities, all the deans of the sample colleges and the heads of the sample department were included in the study by availability sampling techniques. Sample teachers and workers were randomly selected from each of the sample departments. More specifically, 46 academic managers and 30 administrative officers were included in the study by using availability sampling techniques. Whereas, 218 academic and 22 administrative staff were selected through proportionate, simple random sampling methods (see the summary in Table 1 below).

Table 1: Participants of the study

\begin{tabular}{|c|c|c|c|c|c|}
\hline \multicolumn{6}{|c|}{ Respondent Type * University Type Cross-Tabulation } \\
\hline \multicolumn{2}{|c|}{} & \multicolumn{3}{c|}{ University Type } & Total \\
\cline { 3 - 6 } & Jimma & Mizan-Tepi & Wollega & \\
\hline \multirow{3}{*}{ Respondent Type } & Teacher & 104 & 68 & 46 & 218 \\
\cline { 2 - 6 } & Academic Manager & 24 & 16 & 6 & 46 \\
\cline { 2 - 6 } & Office Worker & 8 & 8 & 6 & 22 \\
\hline
\end{tabular}




\begin{tabular}{|c|c|c|c|c|c|}
\hline & Administrative Officer & 14 & 9 & 7 & 30 \\
\hline Total & 150 & 101 & 65 & 316 \\
\hline
\end{tabular}

\section{Instruments of Data Collection}

In this study, data were collected through two major instruments. These are questionnaire and interviews. Each of instruments is discussed as follows:

\section{Questionnaires}

Two sets of questionnaires were used to assess the multicultural competences of educational leaders in HEIs. The use of questionnaires is decided with the conviction that it makes respondents to freely indicate their viewpoints regarding multicultural competences in the public universities. It is also believed that questioners are appropriate tools to collect data from a large number of participants within a relatively short period of time. The two sets of questionnaires were designed in line with the nature of data required from the participants. The first set of questionnaire was administered to academic and administrative staff and the second questionnaire for the educational managers (academic and administrative officers). The questionnaires were designed by consulting relevant literatures in the area of multiculturalism. Accordingly, particular statements that indicate the multicultural competences of the leaders were identified. Then questionnaires were categorized in to different major sections and finally contextualized to fit to the particular setting of the study.

\section{Interview}

In this study, face-to-face semi-structured interviews were used to elicit relevant information on the attitudes and perceptions of the participants regarding multicultural competences in the public universities. As Cohen, Manion, \& Morrison, remark “... the interview is a flexible tool for data collection, enabling multi-sensory channels to be used: verbal, non-verbal, spoken and heard ... (2007, p. 349)". It provides an opportunity to get a detailed data from the relatively smaller numbers of participants. Hence, the interview items were designed based on a rigorous search of the literature review. All the informants were asked the same items in the same arrangement. The interviews were carried out on face to face basis. University officials (vice-presidents, administration team leaders, college deans) and senior teachers were interviewed from the three universities.

\section{Validity and Reliability Checks}

The study, as indicated earlier, involved the collection of both quantitative and qualitative data. Regarding the qualitative data, the items of 
the interviews were developed by consulting substantial works and literature regarding the multicultural competences. They were then modified, omitted as well as added as per the qualitative data. Regarding the validity of the questionnaires, prior to the main data collection phase, a pilot study was carried out to maintain the reliability of the questionnaire items. Besides, the questionnaires were presented to the groups of experts at Jimma University, college of education and behavioural sciences for professional comments. The analysis of the pilot study data indicated that the sub-scales of the questionnaire have good item characteristics in terms of internal consistency and homogeneity of the items contained in each sub-scale. The results showed that the reliability coefficient (Cronbach Alpha) for the educational leaders' questionnaire ranges from 0.840-0.963 and it ranges from 0.8560.932 for the workers' questionnaire, which are considered very good for the purpose of this study. The results of the pilot study have not been included in the final results.

\section{Data analysis Methods}

In this study, the data collected through the questionnaires were coded, entered, cleaned and analysed using the Statistical Package for Social Sciences (SPSS 20) computer software. The quantitative data were analysed using inferential statistics such as mean, standard division, t-tests and one-way ANOVA. The qualitative data were also transcribed, coded and interpreted thematically. The one-way ANOVA was conducted, based on results of inter-item correlation and factor analysis of data, to examine differences in perceptions among the different groups of respondents in the university as well as among the universities. An independent sample t-test was computed to examine the significant perception differences that might exist between university leaders and workers groups. Prior to the independent sample ttest, Levene's Test for Equality of Variances was carried out to check the equality of the variances between the two groups. Based on the results of the Levene's test, equality of variances were taken in to consideration in computing the independent t-test when there are no statistically significant variances between the mean values of the two groups. On the other hand, when statistically significant variances between the mean values of the two groups are found, equality of variances was not taken in to consideration in computing the independent t-test. The interview transcripts were analysed for descriptions and patterns related to themes indicated in the conceptual framework of the study and the basic research questions. Analysis of quantitative data is displayed first and then corroborated by qualitative data analysis in the form of texts and quotes. 


\section{Ethical Issues}

Even though the data collected for this study are not politically, socially or physically sensitive in nature, ethical issues are considered important. For the survey questionnaire, respondents were reminded not to write their name on the questionnaire. The process of getting access to the universities began by requesting permission formally, in writing, through the official channels. The first step the researcher took regarding this matter was to write and explain in detail the purpose of the study and the data-collection methods to be used to the target universities to get permission to conduct the research. The research offices at the sampled universities were requested to issue an ethical clearance certificate for this project. Interviews participants' right to privacy was also maintained through the promise of confidentiality. A number of techniques were included to ensure anonymity and confidentiality in terms of the findings. The participants were informed of the purpose, methods and time frame of the study as it is unethical in terms of human relationships to conduct an investigation when the subjects are unaware of the real purpose.

\section{Results}

\section{Attitudes, knowledge and skills}

An important responsibility for leaders in this new century is the management of diversity, which can take many forms. Leaders play an essential role in helping to bring about equal opportunity and elimination of unfair discrimination in selection and promotion decisions. Leaders can do many things to encourage tolerance and appreciation of diversity in organizations. All leaders in the organization should share the responsibility for improving diversity and ensuring equal opportunity (Yukl, 2010). But doing so needs the leaders to be multiculturally competent. At individual level, leaders' cultural attitude, cultural knowledge and skills are identified to be the chief components of multicultural competences by various literatures and models of multicultural competence (Sue, 2001; Kim-Godwin et al., 2001). Cultural attitude refers to a sensitivity and understanding of one's own and others cultural identity as it manifests itself through our beliefs, values and practices as well as our biases. Cultural knowledge is related with having knowledge of other cultures' beliefs, values and practices, which allow for an understanding of different worldviews. For example, it be conceptualised as university leaders' knowledge concerning the dynamics that occur when two or more groups confront stereotypes and political or power differentials. Knowledge of differences in communication styles, etiquette, problem-solving methods and the like.

Cultural skills refer to the synthesis and applications of both awareness and knowledge. Central to those skills is the ability to 
communicate across cultures and understand how culture influences the content (Pope, Reynolds, \& Mueller, 2004). In line with this, an attempt was made to assess (see Table 2 below) the perceptions of workers and managers regarding the multicultural attitude, knowledge and skills of the university leaders.

Table 2: An independent sample t-test for leaders' multicultural attitudes, knowledge and skills

\begin{tabular}{|c|c|c|c|c|c|c|}
\hline & Respondents & Mean & SD & $\mathrm{df}$ & $\mathrm{t}$ & sig \\
\hline \multirow{2}{*}{ Attitudes } & workers & 3.13 & 1.02 & \multirow{2}{*}{223.07} & \multirow{2}{*}{-10.256} & \multirow{2}{*}{.000} \\
\hline & managers & 4.08 & .521 & & & \\
\hline \multirow{2}{*}{ Knowledge } & workers & 3.13 & 1.00 & \multirow{2}{*}{125.06} & \multirow{2}{*}{-5.529} & \multirow{2}{*}{.000} \\
\hline & managers & 3.75 & .583 & & & \\
\hline \multirow{2}{*}{ skills } & workers & 2.79 & 1.02 & \multirow{2}{*}{184} & \multirow{2}{*}{-2.074} & \multirow{2}{*}{.039} \\
\hline & managers & 3.41 & .701 & & & \\
\hline
\end{tabular}

Though both groups apparently have evaluated the multicultural attitude and knowledge of the leaders as positive, their perceptions significantly differ from one another (attitude, $t$ (223.078) $=-10.256, p=$ $0.00)$ and knowledge, $t(125.063)=-5.52, p=0.00)$. More specifically, the managers have higher positive evaluation of the cultural attitudes $(\mathrm{M}=4.08$; $\mathrm{SD}=.52419)$ and cultural knowledge $(\mathrm{M}=3.75$; $\mathrm{SD}=.583)$ of their own as compared to the perceptions of the workers regarding the cultural attitudes $(\mathrm{M}=3.13 ; \mathrm{SD}=1.021)$ and cultural knowledge $(\mathrm{M}=3.1366, \mathrm{SD}=1.00583)$ of the leaders.

Regarding the cultural skills of the leaders, the difference between the perceptions of the two groups were statistically significant, $t$ (184) = 2.074, $p=.039$, in that the managers have a positive evaluation of the cultural skills of the leaders $(\mathrm{M}=3.41, \mathrm{SD}=.701)$ in contrast to the perceptions of the workers $(\mathrm{M}=2.79, \mathrm{SD}=1.02)$.

The qualitative data also indicated that some educational leaders are not culturally aware and sensitive to valuing and respecting differences. Some leaders also lack adequate knowledge and understanding about how discrimination and stereotyping affects in their work; about ethnic and cultural differences, and their social impact on others. Besides, efforts to engage with diversity or to promote a multicultural environment were often ad-hoc, resulting in efforts reaching a few individuals, without affecting the outlook and practice of the universities as institutional entities. Efforts were also insufficient to comprehensively address the different challenges faced by members of the university staff in engaging with diversity. Progress in addressing gender issues was still limited, including in terms of women's empowerment, and the rate at which opportunities are utilised by men and women is still skewed in favour of men, as with the low numbers of female lecturers. 
Table 3: One-way ANOVA on MC of Educational Leaders

\begin{tabular}{|c|c|c|c|c|c|c|}
\hline MC & & $\begin{array}{l}\text { Sum } 0 \\
\text { Squares }\end{array}$ & $\mathrm{df}$ & Mean Square & $\mathrm{F}$ & Sig. \\
\hline \multirow{3}{*}{ Attitudes } & Between Groups & 5.700 & 2 & 2.850 & 2.813 & .062 \\
\hline & Within Groups & 292.759 & 289 & 1.013 & & \\
\hline & Total & 298.459 & 291 & & & \\
\hline \multirow{3}{*}{ Knowledge } & Between Groups & 9.784 & 2 & 4.892 & $5.414^{* *}$ & $.005^{*}$ \\
\hline & Within Groups & 215.950 & 239 & .904 & & \\
\hline & Total & 225.733 & 241 & & & \\
\hline \multirow{3}{*}{ skills } & Between Groups & 10.847 & 2 & 5.424 & $5.506^{* *}$ & $.005^{*}$ \\
\hline & Within Groups & 180.264 & 183 & .985 & & \\
\hline & Total & 191.111 & 185 & & & \\
\hline
\end{tabular}

An analysis of ANOVA was computed to examine if there were differences in the staff perception with respect to the leadership attitudes, knowledge and skills across the three Universities. Significant differences were found in staff's responses across the three universities, regarding leaders MC knowledge $\mathrm{F}(2,169)=4.892, \mathrm{p}=.005$ and $\mathrm{MC}$ skills, $\mathrm{F}(2,16)$ $=5.506, \mathrm{p}=.005$.

Table 4: Post Hoc Test for MC of Educational leaders

\begin{tabular}{lllllll}
\hline \multicolumn{3}{c}{ MC Knowledge } & \multicolumn{3}{c}{ MC skills } \\
\hline Universities & JU & MTU & WU & JU & MTU & WU \\
\hline JU & & .100 & $.006^{*}$ & & $.019^{*}$ & $.017^{*}$ \\
\hline MTU & & & .390 & & & .904 \\
\hline
\end{tabular}

The Tukey post-hoc multiple mean comparisons showed that there were significant difference between $\mathrm{JU}(\mathrm{M}=3.45, \mathrm{SD}=.899)$ and $\mathrm{MTU}(\mathrm{M}=$ 2.93, $\mathrm{SD}=.928$ ) on the subject of leaders MC knowledge. Moreover, in account of leaders MC skills, statistically significant differences were exhibited between $\mathrm{JU}(\mathrm{M}=3.09, \mathrm{SD}=1.04875)$ on the one side, and $\mathrm{WU}$ $(\mathrm{M}=2.5614, \mathrm{SD}=.73155)$ and $\mathrm{MTU}(\mathrm{M}=2.6484, \mathrm{SD}=.1 .04785)$ and on the other side.

\section{Discussion}

The study indicates that though the leaders in the public universities had better awareness and understanding of cultural issues, they were not able to adequately synthesize and apply their knowledge and attitudes in creating effective communication and interaction across their campuses. The findings of the study indicated that the multicultural attitude, knowledge and skills of the university leaders were generally perceived to be low by the workers as compared to the perceptions of the managers participated in study. The study also revealed that there were differences between the perceptions of the 
managers and workers in this regard. The managers have shown a relatively positive perception for their own multicultural attitude, knowledge and skills. The fact that the managers had exhibited positive evaluations for their own MCs is in line with the previous research findings that "self-ratings of one's own leader behaviour are prone to bias" (Bass \& Riggio, 2006, p. 20).

Similarly the perceptions of workers regarding the competencies of their leaders could also be prone to biases. Though, the effectiveness of the leader, among other things, is indicated by the followers perceptions, research also indicates that the perceptions of followers regarding the performances and competencies of their leaders can be influenced by the extent of the similarities of the values, beliefs, and other such qualities as religion, gender, ethnic background of the followers to that of their leaders (Yukl, 2010). Nevertheless, it is vital for leaders, whatsoever the sources of their leadership powers might be, to take how they are being perceived by their followers in to considerations (Bass \& Riggio, 2006). The perception of the followers has important implications for the leaders and the institutions they are leading as the "amount of legitimate power and discretion allowed a leader depends on the perception by followers" (Yukl, 2010, p. 135). That means, the leader can only be able to influence the followers if the followers are willing to expose themselves to such influence which in turn depends on how they perceive the leader.

The study also found out that there are significant statistical differences among the sample universities pertaining to their leaders' multicultural competencies. The mean ratings of JU is higher than the MTU and WU implying that the leaders in the JU had relatively better MCs as compared to the rest two universities. This may indicate that the leadership in JU was relatively in a better position in creating an environment that is respectful of all people; in reflecting cultural diversity in terms of sex, ethnicity, language and religion among workers; in providing cultural competency training for the staff; and in identifying ethnic/cultural competence as an organizational concern. This might be attributed to the length of the universities years of establishment in that $\mathrm{JU}$ is included in the first generations of Ethiopian public universities that counted for a relatively longer years after its establishment as compared to the MTU and WU. This presumption is in line with the notion that MC as a sub culture of the universities to occur, "there must be a history of shared experience that, in turn, implies some stability of membership in the group" (Schein, 2004). Further research in the area might be sought to identify causes for such differences in the MCs of educational leaders across universities.

The other barrier that the study uncovered is that the university leaders and workers in this study had moderate mean scores on their multicultural knowledge, attitudes, skills and diversity actions. The 
university leaders, academic and administrative staff did not have a considered perspective on pluralism as an important viewpoint to engage with the multicultural context of the universities, in which diverse communities co-exist. In addition, there were limited spaces and opportunities for the staff to develop skills and experience in the management of difference as an important aspect of their work and with their interaction with other members of the university community. The staff associations were weak and poorly equipped to provide or promote opportunities for skills development in the management of diversity. Lecturers did not generally receive any preparation on managing within a multicultural setting. It was learned that the leaders were unaware of cultural influences in the HEIs settings.

\section{Conclusion}

The study revealed that the leadership in the sample universities were not adequately equipped with MCs and hence weren't in a better position in creating institutional ethos and climate which are critical in promoting multicultural sensitivity within the universities. In the absence of multicultural leadership, an organization may sink into hegemonic thinking and exclusion of diversity in opinion. In the situation where leaders' multicultural competencies, which is an important responsibility for leaders in this new century, are lacking, it is hardly possible to bring about equal opportunity and elimination of unfair discrimination.

The study also found out that there was a gap between the perceptions of managers and workers pertaining to the leaders MCs. This might be due to the short comings in the communication process of the universities, implying that employees were not clearly aware of the values, actions and the competencies of their leaders in case leaders possess any positive qualities of leadership.

\section{Recommendations}

Effective global leaders should increase their capabilities to manage the complexity of diverse people, understand and respect differences, make necessary adjustment in the leadership, and be ready for opportunities and challenges that come alone. The findings of the study call for the need to prepare university leaders with multicultural knowledge, skills, and dispositions. As the multicultural competences of educational leaders in the public universities under consideration were low, the need for continuous multicultural leadership development endeavours for the existing as well as newly recruited leaders are crucial to be considered by the public universities. The findings from this study also suggest that the university leaders need to become multiculturalists and social reconstructionists. Such 
findings emphasize the need for multicultural leadership that helps change culturally problematic institutions into multicultural organizations. In order to make these changes, leaders should be ethically and multiculturally accountable for ensuring an institutional identity open to cultural plurality and ready for the challenge of the institutionalizing the value of individual differences. In HEIs, this will allow the institutions to fulfil their aim of representing plurality and democracy. The universities should build on cultural differences to build a culturally diverse, nurturing climate that fosters creativity and critical thinking. Such a climate is central to acquiring and retaining staff from culturally diverse backgrounds that can help in making the institution flourish. Besides, educational leaders in the public universities need to continuously communicate their values, beliefs, pertaining to multiculturalism and diversity in their campuses so that the followers will have better understanding of their leaders. Furthermore, the study recommends for further research endeavours to investigate the causes as to why leaders' multicultural competence varies in public universities.

\section{References}

Abreu, J. M., Chung, R. H. G., \& Atkinson, D. R. (2000). Multicultural counselling training: Past, present, and future directions. The Counselling Psychologist, 28, 641-656.

Ameny-Dixon, G. (2004). Why multicultural education is more important in higher education now than ever: A global perspective. International Journal of Scholarly Academic Intellectual Diversity, 8 (1).

Andersen, F. (2012). The concept of multiculturalism and implications for school leadership. Retrieved September 29, 2015 from , from http://www.emasa.co.za

Bass, B.M. \& Riggio, R.E (2006). Transformational leadership. Mahwah, New Jersey: Lawrence Erlbaum Associates, Inc

Chin, J. L. (2009). The Dynamics of Gender, Race, and Leadership. In R. H. Klein, C. A. Rice, \& V. L. Schermer (Eds.), Leadership in a changing world: dynamic perspectives on groups and their leaders (pp. 73-90). Lanham: he Rowman \& Littlefield Publishing Group, Inc.

Chuang, Fang (2013). Essential Skills for Leadership Effectiveness in Diverse Workplace Development. Online Journal for Workforce Education and Development, 6(1).

Cohen, L., Manion, L., \& Morrison, K. (2007). Research Methods in Education (6 ed.). Abingdon: Taylor \& Francis.

Connerley, M. L., \& Pedersen, P. B. (2005). Leadership in a diverse and multicultural environment: Developing awareness, Knowledge, and skills . Sage Publications, Inc. 
Creswell, J. W. (2009). Research design: Qualitative, quantitative, and mixed methods approaches (3 ed.). New Delhi: SAGE Publications India Pvt. Ltd.

Dimmock, C. \& Walker, A. (2005). Educational Leadership: Culture and Diversity. London: Sage.

Federal Democratic Republic of Ethiopia (2009). Higher education proclamation (No. 650/2009), Federal Negarit Gazeta 15(64): 4976-5044. Addis Ababa, 17 September 2009.

Jupp, V. (2006). The Sage Dictionary of Social Research Methods. London: SAGE Publications Ltd.

Kim-Godwin, Y.S., Clarke, P.N. and Barton, L. (2001). A model for the delivery of culturally competent community care. Journal of Advanced Nursing, 35:918-25.

Lumby, J. \& Coleman, Marianne (2007). Leadership and Diversity: Challenging Theory and Practice in Education, SAGE Publications Ltd: London.

Ministry of Education (2010). Education Statistics Annual Abstract: 2008/9. Addis Ababa: Ministry of Education.

Ministry of Education (2011). Education Statistics Annual Abstract: 2010/2011. Addis Ababa: Ministry of Education.

Ministry of Information (2004). Facts about Ethiopia. Addis Ababa, Ethiopia: Press and Audiovisual Department, Ministry of Information

Minstry of Education (2012). Education Statistics Annual Abstract 2004 E.C (2011/2012) . Addis Ababa. doi: www.moe.gov.et

Minstry of Education(1994). Education and Training Policy. Addis Ababa.

Northouse, P. G. (2013). Leadership: Theory and Practice (6 ed.). Los Angeles: Sage Publications.

Pope, R.L., Reynolds, A.L. \& Mueller, J.A. (2004). Multicultural competence in student affairs. San Francisco, CA: JosseyBass.

Sue, D.W., Carter, R.T., Casas, J.M. et al (eds) (1998). Multicultural Counselling Competencies: individual and organizational development. Thousand Oaks, CA: Sage.

Sue, D. W. (2001). Multidimensional Facets of Cultural Competence. The Counseling Psychologist , 29 (6), 790-821.

Webb, L., Darling, J., \& Alvey, N. (2014). Multicultural Leadership Development in the 21st Century . WHITE PAPER.

World Bank (2012). Ethiopia Overview. Retrieved on the date January, 2013 from http://www.worldbank.org/en/country/ethiopia/overview.

Yukl, G. (2010). Leadership in Organizations (7th ed.). New Jersey: Prentice Hall. 